\title{
Survey on the attitudes of dental hygiene students towards treating elderly patients
}

\author{
Grandjean, Marie-Laure ; Morier, Chloé ; Piccardi, Carlotta ; Srinivasan, Murali
}

\begin{abstract}
Objective This questionnaire-based survey assessed the attitudes of dental hygiene students towards treating elderly patients. Methods The 14-item Geriatric Attitude Scale (GAS-14) questionnaire was used in this survey. A further set of 9 questions evaluated the opinions of the students towards the existing geriatric curriculum in their respective institutions. Students from five dental hygiene schools from three countries (Switzerland, Belgium, Canada) participated in this survey. General demographic information from the participants were collected. Mean GAS-14 scores were calculated; ANOVA and Bonferroni tests were used for statistical analyses $(\mathrm{p}<0.05)$. Results 385 students (Switzerland: $n=157$, mean-age $=25.38 \pm 4.6 y$, Belgium: $n=82$, mean-age $=27.58 \pm 12.8 \mathrm{y}$; Canada: $\mathrm{n}=146$, mean-age $=25.95 \pm 12.3 \mathrm{y}$ ) completed the survey for a response rate of 86.3\%. The overall GAS-14 scores for Switzerland, Belgium, and Canada were 3.61 $\pm 0.42,3.24 \pm 0.37$, and 3.32 \pm 0.36 , respectively. Switzerland scored significantly higher than Belgium and Canada $(\mathrm{p}<0.0001)$. Overall scores revealed a significant effect of progressive training $(\mathrm{p}=0.010)$. The GAS-14 score was influenced by the nationality of the participants $(\mathrm{p}<0.0001)$, but not influenced by sex, age, origin, religion, marital-, and accommodation-, statuses. Majority of the students (75.8\%) agreed that geriatric dentistry was an important part of their education. $77.4 \%$ agreed that they would like hands-on experience in treating the elderly patient during their education. $85.1 \%$ of the participants considered mobile dental clinics as a good solution for the provision of dental care to the institutionalized elders. Conclusions The general attitudes of DH students towards treating the elderly patients are on an acceptable level and improved as they progressed through their dental hygiene academic programs.
\end{abstract}

DOI: https://doi.org/10.1111/idh.12486

Posted at the Zurich Open Repository and Archive, University of Zurich

ZORA URL: https://doi.org/10.5167/uzh-195909

Journal Article

Accepted Version

Originally published at:

Grandjean, Marie-Laure; Morier, Chloé; Piccardi, Carlotta; Srinivasan, Murali (2021). Survey on the attitudes of dental hygiene students towards treating elderly patients. International Journal of Dental Hygiene, 19(2):176-183. DOI: https://doi.org/10.1111/idh.12486 
PROF. MURALI SRINIVASAN (Orcid ID : 0000-0003-3365-576X)

Article type : Original Article

Title:

Short title:

Authors:

Author Affiliations:

\section{Survey on the attitudes of dental hygiene students towards treating elderly patients}

Dental hygiene students' attitudes on geriatric patients Marie-Laure Grandjean, ${ }^{1}$ Chloé Morier, ${ }^{2}$ Carlotta Piccardi, ${ }^{3}$ Murali Srinivasan ${ }^{1}$

1- Clinic of General, Special Care and Geriatric Dentistry, Center of Dental Medicine, University of Zurich, Zurich, Switzerland.

2- Haute Ecole Libere de Bruxelles, Brussels, Belgium

3- Artevelde University of Applied Sciences, Ghent, Belgium.

Corresponding author: Prof. Murali Srinivasan

Clinic Director, Clinic of General, Special care and Geriatric Dentistry, Center of Dental Medicine, University of Zurich, Plattenstrasse 11, 8032, Zurich, Switzerland.

Tel No: +41446343380

email: murali.srinivasan@zzm.uzh.ch

Murali Srinivasan: 0000-0003-3365-576X

M.L.G. \& M.S. conceived the ideas; M.L.G., C.M., C.P. contributed to data collection; M.L.G., \& M.S. analyzed the data; M.S. led the writing; M.L.G., M.S., C.M., C.P., critically revised the manuscript and gave final approval.

Conflicts of Interests: None

Acknowledgements: students from the various participating institutions for their

This article has been accepted for publication and undergone full peer review but has not been through the copyediting, typesetting, pagination and proofreading process, which may lead to differences between this version and the Version of Record. Please cite this article as doi: 10.1111/IDH.12486

This article is protected by copyright. All rights reserved 
cooperation in the successful completion of this survey. The authors would extend their special thanks to Dr. Petra Hofmänner, from Medi School of Dental Hygiene in Bern, Mrs. Sandra Augustin-Wolf from Careum School of Dental Hygiene in Zurich, and Ms. Diane Beauregard from Maisonneuve School of Dental Hygiene in Quebec for their gracious support in completing this study. 
Abstract (words: 249/250)

Objective: This questionnaire-based survey assessed the attitudes of dental hygiene students towards treating elderly patients.

Methods: The 14-item Geriatric Attitude Scale (GAS-14) questionnaire was used in this survey. A further set of 9 questions evaluated the opinions of the students towards the existing geriatric curriculum in their respective institutions. Students from five dental hygiene schools from three countries (Switzerland, Belgium, Canada) participated in this survey. General demographic information from the participants were collected. Mean GAS-14 scores were calculated; ANOVA and Bonferroni tests were used for statistical analyses $(p<0.05)$.

Results: 385 students (Switzerland: $n=157$, mean-age $=25.38 \pm 4.6 y$, Belgium: $n=82$, mean-age $=27.58 \pm 12.8 \mathrm{y}$; Canada: $n=146$, mean-age $=25.95 \pm 12.3 y$ ) completed the survey for a response rate of $86.3 \%$. The overall GAS-14 scores for Switzerland, Belgium, and Canada were $3.61 \pm 0.42,3.24 \pm 0.37$, and $3.32 \pm 0.36$, respectively. Switzerland scored significantly higher than Belgium and Canada $(p<0.0001)$. Overall scores revealed a significant effect of progressive training $(p=0.010)$. The GAS-14 score was influenced by the nationality of the participants $(p<0.0001$ ), but not influenced by sex, age, origin, religion, marital-, and accommodation-, statuses. Majority of the students $(75.8 \%)$ agreed that geriatric dentistry was an important part of their education. $77.4 \%$ agreed that they would like hands-on experience in treating the elderly patient during their education. $85.1 \%$ of the participants considered mobile dental clinics as a good solution for the provision of dental care to the institutionalized elders.

Conclusions: The general attitudes of $\mathrm{DH}$ students towards treating the elderly patients are on an acceptable level and improved as they progressed through their dental hygiene academic programs.

Key Words: Geriatrics attitude scale, Elders, Aged patients, Dental Hygienists, Ageism 


\section{Introduction}

Oral hygiene maintenance in institutionalized geriatric patients dependent for care remains a perennial problem. ${ }^{1-3}$ It cannot however be emphasized enough that inadequate oral hygiene can result in not only the deterioration of oral-health, but also general health; whereby decreasing the quality of life in multi-morbid geriatric patients dependent for care. ${ }^{4}$ Ineffective oral hygiene results in plaque retention and increases the oral bacterial flora. Institutionalized older adults dependent for care show a higher susceptibility to pulmonary infections, bacterial septicemias, bacterial endocarditis and other health complications due to neglected oral health. ${ }^{5}$ In the cases associated with pneumonia-related deaths in institutionalized geriatric patients, the etiology has frequently been neglected oral hygiene. ${ }^{6,7}$ Another predisposing condition that further potentiates health risk is dysphagia, which has been held accountable as a primary cause for aspiration pneumonia in frail individuals. ${ }^{8}$ Therefore, maintaining oral hygiene in institutionalized frail elders is cardinal and likely help reduce the mortality from aspiration pneumonia. $^{9}$

Currently, in most institutions, oral care for the institutionalized elders is provided by caregiving staff and is considered an unpleasant task. ${ }^{10,11}$ Performing effective oral hygiene measures on such dependent elders is a tedious task and warrants all facets of physical and psychological endurance. ${ }^{1-3}$ The problems faced by the caregiving staff in performing effective oral care is compounded not only by the elders' compliance with performing the necessary oral hygiene, but also the physical demands of the task itself. Moreover, a lack of training of the caregiving staff in this field further limits the possibility of effective oral being provided.

In order for effective oral care to be provided to care-dependent elders, adequate training to the caregiving staff needs to be established, or the long-term care facility (LTCF) should have an access to a dentist and/or a dental hygienist. Often emergency dental care is sought by the institutions rather than preventive dental care. In most instances these emergency situations could be avoided if the care-dependent elders had a regular periodic recall for their oral health examinations conducted by a dental hygienist. ${ }^{12}$

Most oral health related problems with dependent elders are frequently associated with ineffective oral hygiene. This can be assessed and prevented by routine hygiene 
maintenance performed by a dental hygienist. However, not many hygienists are available to routinely visit institutionalized elders, or perhaps the care facilities do not employ dental hygienists and dental assistants. Currently, majority of the hygienists are attached to either private dental clinics or in hospital/university-setting dental clinics. It is not certain whether this trend is due to a lack of experience in managing complex and age advanced individuals, or in their attitudes towards treating the elders, or not in-depth coverage of geriatrics in their curriculum. ${ }^{13,} 14$ In the future, dental hygienists will be crucial in forming an integral part in maintaining and performing oral care in caredependent institutionalized elders. Dental hygienists possess the knowledge base to assess oral diseases and conditions and may well substitute dentists for providing the necessary oral care in terms of frequent examinations and hygiene procedures, in the future. It is imperative that the education of the dental hygiene students includes exposure to complex geriatric patients with needs. It is critical that future dental hygienists and current dental hygiene students have a positive and accepting attitude towards treating dependent institutionalized elders.

\subsection{Aim of the Survey}

The aim of this survey was to assess the attitudes of dental hygiene students towards elderly patients. The survey also evaluated the opinions of the students on the adequacy of the geriatric modules present in their curriculum and their confidence in treating elders unsupervised.

\subsection{Study Hypothesis}

The null hypothesis set for this survey was that, irrespective of the year of study, there would be no differences in the attitudes of the dental hygiene students towards elderly patients. A secondary hypothesis is that there will be no differences in the attitudes of the dental hygiene students towards elderly patients irrespective of the country (Switzerland, Belgium and Canada) in which they study.

\section{Methodology}

This multicenter survey was conducted in five dental hygiene schools (Bern, Zurich, Brussels, Ghent, Quebec) in three countries (Switzerland, Belgium, and Canada). The 
participating dental hygiene schools from Switzerland and Canada were diploma-level institutions, while the participating dental hygiene schools from Belgium offered bachelorlevel courses. There was no external funding received for the conception, execution and completion of this survey. The survey was reviewed by ethics committee in Switzerland (Kantonale Ethikkommission Zurich). The committee's decision was that the study did not fall in the scope of the Human Research Act (HRA), therefore did not require a formal authorization from the ethics committee (BASEC-Nr. Req-2019-00840).

\subsection{Survey Questionnaire}

The 14-item validated geriatrics attitudes scale (GAS-14), ${ }^{15}$ was used in this survey to assess the attitudes of the dental hygiene students towards treating elderly patients (appendix 1).

The 14-item questionnaire was designed with a 5-point Likert-scale response type per item (1-strongly disagree, 2-somewhat disagree, 3-neutral, 4-somewhat agree, 5strongly agree). There were positively or negatively worded items in the questionnaire. The following items were negatively worded: $2,3,5,6,8,10,11,12$, \& 13; for a negatively worded item in the questionnaire the scores were reversed (i.e., 1 to 5, 2- 4, 3 stays, 4 to 2 , and 5 to 1 ) before being added to the total GAS-14 score.

Along with the GAS-14 questionnaire a supplementary section with 9-items was also included (appendix 1). The supplementary questionnaire was developed by the authors and was validated internally within the clinic for geriatric dentistry at the dental school in Zurich. The questionnaire was tested on the dental students and was used in a previous study with similar outcome. ${ }^{16}$ This 9-item section assessed the students' opinions on the current geriatric curriculum in their present syllabus. The 9-item section also had a Likert-scale response. Demographic data about the participants such as: age, sex, nationality, country of origin, religion, marital and accommodation statuses, whether they live with their parents or grandparents or both, along with their year of study were collected in the same questionnaire (appendix 1). Previous studies have demonstrated that exposure or familiarity with aged persons has shown to influence or improve the attitudes towards elders. ${ }^{17-20}$ Hence, the demographic data pertaining to residing with grandparents and family status was requested.

\subsection{Translation}


Translation of the GAS-14 was conducted as prescribed by the Medical Outcomes Trust criteria. ${ }^{21}$ The GAS-14 questionnaire was translated from English to French, and English to German; then back-translated to English. The translated and back-translated questionnaires were reviewed by the investigators (M-LG, \& MS) and diagnosed for any problems in understanding. Appropriate corrections were made accordingly in consensus with the translators.

\subsection{Participants}

The survey included the students from dental hygiene schools in Switzerland (Bern and Zurich), Belgium (Brussels, and Ghent) and from Canada (Quebec). The printed questionnaires were administered to the students in a classroom session and was supervised by one investigator from each of the respective schools for clarification of doubts during the completion of the questionnaire. The students were given adequate time-frame to complete the questionnaires. The questionnaire responses were anonymized and no information regarding the identities of the respondents was collected. Participation in the survey was voluntary. The centers in Bern and Zurich administered the German version of the GAS-14, while Brussels and Quebec used the French version, and Ghent employed the original English questionnaire.

2.4 Statistical Analysis:

Mean GAS-14 was calculated and was verified for a normal distribution, ANOVA and post hoc tests were applied for differences between the countries (inter-group) and within each country between the years of study (intra-group). The level of significance was set to $p<0.05$. Statistical analyses were performed using a statistical software package (SPSS Statistics, version 25.0, IBM Incorporated, NY, USA).

\section{Results}

A total of 385 dental hygiene students (mean age: $26.06 \pm 10.0$ ) from five dental hygiene schools in three countries participated in this survey. The survey response rate was $86.3 \%$. The demographic characteristics of the participants are shown in table 1. Differences between the participating countries were present for the number of participants $(p=0.010)$, nationality $(p<0.001)$, and the marital status $(p<0.001)$. No other differences were found in the demographic characteristics between the participants.

3.1 Geriatric Attitude Scale-14 scores 
The mean GAS-14 scores of the participants is categorized by the years of study, along with the comparisons within and between the centers is shown in table 2. Dental hygiene students from Switzerland scored significantly higher than the students from Belgium $(p<0.001)$ and Canada $(p<0.001)$. Within-country comparisons revealed that for Switzerland, the students from the first year scored higher than the students from the second $(p=0.0004)$ and third (n. s.) years. In Belgium, the students from the first year scored significantly lower than the second $(p=0.044)$ and third $(p=0.005)$ years. There were no differences in the scores between the study years for Canada. When the results were pooled, a significant effect of progressive training was observed $(p=0.010)$. When analyzing the influence of demographic factors on the GAS-14 scores, nationality of the participants influenced the GAS-14 scores $(p<0.001)$, and a tendency was observed for marital status $(p=0.05)$. Other demographic parameters did not affect the GAS-14 scores (Table 3).

\subsection{Responses to the supplementary questionnaire}

The responses to the supplementary questions related to the geriatric oral health curriculum, the participants' confidence, and their preferences in treating the elderly patients is descriptively reported (Table 4, Figure 1$)$. The majority of the students $(75.8 \%)$ agreed that geriatric oral health was an important part of their education. However, 54.7\% were of a neutral opinion when it came to assessing the adequacy of the geriatric program in their curriculum. $77.4 \%$ agreed that they would like some hands-on experience in treating the elderly patient during their studies. $71.6 \%$ of the participants agreed that they were confident with treating the elders independently on their own; while $45 \%$ of the participants also responded that they would like to be supervised when treating the elderly patient. For the treatment setting, $35.2 \%, 26.6 \%$, and $27.5 \%$ of the participants preferred to treat the elderly patients in a clinic-, hospital-, and nursing homesetting, respectively. Approximately $85.1 \%$ of the participants agreed that the mobile dental clinics were a good solution for the provision of dental care to the elders with limited/or no access to care.

\section{Discussion}

The study was undertaken to assess the attitudes of the dental hygiene students towards elderly patients. The results (overall) of the present study indicate that a significant effect 
of progressive training was observed $(p=0.010)$. Therefore, the null hypothesis has to be rejected. This is in accordance to a previous study that also demonstrate this effect of progressive improvement of the attitudes with increased learning. ${ }^{15}$ However, it is important to note that a decline of the scores from the first year to second year was observed $(p=0.936)$ and then increased in the third year that was significant $(p=0.008)$. This trend was not consistent across all the participating dental hygiene schools and was observed only in the Swiss and Canadian dental hygiene schools. However, in Canada, changes were not significant between the three years in the overall result and this neutral perception has also been observed in previous studies. ${ }^{22}$ Only in Belgium a true progressive effect of advancing training was observed. It was evident that the GAS-14 scores were significantly higher for the students from Switzerland than scores of the students from the other two countries (Belgium and Canada). Hence the secondary hypothesis also has to be rejected. Although many of the demographic factors had no effect on the attitudes of the students, nationality of the students had a significant effect. A possible explanation for this could be the experience, interaction, and familiarity with elderly people may have helped influence the attitude towards elderly. Studies have demonstrated that exposure of undergraduate students to elderly persons improved their attitudes towards the elderly. ${ }^{17-20}$ Also, demographics reveal that developed countries have a higher number of elderly populations especially in Europe, ${ }^{23,24}$ and this could have been a reason why a difference was seen, the participants who are resident from these nations might have had a more positive response. However, this is speculative and further research is warranted to prove this. Furthermore, the geriatric curriculum and the education received in each of these centers may not be similar in terms of practical courses, or the patient cohorts that are presented to the students. This may have been the reason why the participants' responses differed. In Switzerland, viz. Zurich, the dental hygiene school provides an internship to their trainees to visit and observe in a universitysetting dental clinic that is specialized in providing care for that geriatric patients as well as patients with special needs. Furthermore, the Swiss dental hygiene schools have didactic modules focusing on geriatric dentistry in their curricula. These differences in the course structures probably could have been the reason why the overall GAS-14 scores were higher for Switzerland than the other centers. 
Studies in literature have demonstrate mixed findings when evaluating the attitudes of medical and dental students towards older adults, some with positive results while others have revealed neutral opinions. ${ }^{25-28}$ Revising didactic courses and, practical experiences to incorporate the geriatric oral care in the current academic curriculum may help to positively increase or improve students' attitudes towards treating a geriatric population. Increasing the possibilities to treat and care for geriatric patients could prepare dental hygiene students to be better prepared to treat elderly patients after graduation. This has been elucidated by our survey where a majority of the participants $(77.4 \%)$ have noted that they would prefer to have hands-on training with geriatric patients during their study period.

This study however, has limitations worth discussing as they could have played a role in influencing the study outcome. The questionnaire used in this study was not a purpose-built ageism questionnaire for dental/dental hygiene students. Hence, it may have undermined the detection of attitudes of the dental hygiene students and may have been less sensitive. Nevertheless, it is important to bear in mind that the GAS-14 questionnaire has a sound psychometric characteristic with no floor/ceiling effect, and is able to reveal sufficient internal consistency reliability. ${ }^{15,28}$ All measures were taken to ensure that the questionnaire-dependent errors were minimized. The questionnaire was translated and back-translated to the respective local languages of the participating centers using the strict medical outcomes trust criteria. ${ }^{21}$ An aspect that could have influenced the results could have been the sample size. A true sample size calculation was not deemed possible as similar dental studies in literature that measure the same outcome do not currently exist, for a sample size calculation. However, an attempt to acquire the maximum number of possible participants for each participating center was done. The questionnaires were circulated during classroom sessions when a maximum attendance was expected. Another important point to be borne in mind is that although centers from three different countries participated in this survey, this survey may still not be considered nationally representative, as all the hygiene schools from each country did not participate. The participating dental hygiene schools in Switzerland and Canada provided diploma-level-, while the participating institutions from Belgium were bachelorlevel educations. The level of education in preparing the dental hygiene students for caring for a geriatric population, in each of the participating dental hygiene schools may 
have differed due to the difference in academic curricula. This aspect could have been also a factor in influencing the difference in the results between the centers. To include all the relevant dental hygiene schools from each participating country is a huge undertaking with complex logistical and financial constraints. However, this study did manage to involve three countries and the results may be considered meaningful for educational institutions.

\section{Conclusions}

The general attitudes of dental hygiene students towards treating the elderly patients are on an acceptable level and improved as they progressed through their dental hygiene academic programs. Incorporation of more geriatric modules along with extending opportunities to treat more older adults during the dental hygiene students' education can further help prepare the dental hygiene students better for the future for providing the necessary care to a geriatric population.

\section{Clinical Relevance}

\subsection{Scientific rationale}

Globally the population is ageing and retaining their natural teeth resulting in more oral health care needs. There is a heightened need for educating the current undergraduates dental hygiene students to provide oral care to older adults. An evaluation of the dental hygiene students' attitudes towards treating older adults is necessary to plan and structure a purposeful curriculum in their respective academic program.

\subsection{Principal findings}

The attitudes of the dental hygiene students towards older adults are at an acceptable level. The participants agreed that the geriatric dentistry is an important aspect of their study curriculum, but indicated a neutral attitude towards the sufficiency of the geriatric modules in their present curricula. The majority of participants agreed that practical hands-on experience in treating geriatric patients during their study is important and that mobile dental services are a practical solution for elders with limited access to care.

\subsection{Practical implications}


Knowledge and insight on the attitudes of undergraduate students towards elders could be useful in improving geriatric teaching curriculum which could in turn improve the delivery and quality of dental care in an older adult population. 


\section{References}

1. de Lugt-Lustig KH, Vanobbergen JN, van der Putten GJ, De Visschere LM, Schols JM, de Baat C. Effect of oral healthcare education on knowledge, attitude and skills of care home nurses: a systematic literature review. Community Dent Oral Epidemiol 2014;42:88-96. doi:10.1111/cdoe.12063

2. De Visschere L, de Baat C, Schols JM, Deschepper E, Vanobbergen J. Evaluation of the implementation of an 'oral hygiene protocol' in nursing homes: a 5-year longitudinal study. Community Dent Oral Epidemiol 2011;39:416-25. doi:10.1111/j.16000528.2011.00610.x

3. Miegel K, Wachtel T. Improving the oral health of older people in long-term residential care: a review of the literature. Int J Older People Nurs 2009;4:97-113. doi:10.1111/j.1748-3743.2008.00150.x

4. Kandelman D, Petersen PE, Ueda H. Oral health, general health, and quality of life in older people. Spec Care Dentist 2008;28:224-36. doi:10.1111/j.17544505.2008.00045.x

5. Quagliarello V, Ginter S, Han L, Van Ness P, Allore H, Tinetti M. Modifiable risk factors for nursing home-acquired pneumonia. Clin Infect Dis 2005;40:1-6. doi:10.1086/426023 6. Abe S, Ishihara K, Adachi M, Okuda K. Tongue-coating as risk indicator for aspiration pneumonia in edentate elderly. Arch Gerontol Geriatr 2008;47:267-75. doi:10.1016/j.archger.2007.08.005

7. Awano S, Ansai T, Takata Y, et al. Oral health and mortality risk from pneumonia in the elderly. J Dent Res 2008;87:334-9.

8. Schmidt J, Holas M, Halvorson K, Reding M. Videofluoroscopic evidence of aspiration predicts pneumonia and death but not dehydration following stroke. Dysphagia 1994;9:7-11.

9. Müller F. Oral hygiene reduces the mortality from aspiration pneumonia in frail elders. J Dent Res 2015;94:14S-16S. doi:10.1177/0022034514552494

10. Forsell M, Sjogren P, Kullberg E, et al. Attitudes and perceptions towards oral hygiene tasks among geriatric nursing home staff. Int J Dent Hyg. 2011;9(3):199-203. 
11. Nicol R, Petrina Sweeney M, McHugh S, Bagg J. Effectiveness of health care worker training on the oral health of elderly residents of nursing homes. Community Dent Oral Epidemiol. 2005;33(2):115-124.

12. Brocklehurst $P$, Macey R. Skill-mix in preventive dental practice--will it help address need in the future? BMC Oral Health. 2015;15 Suppl 1:S10.

13. Harbison LA, Gurenlian JR, Freudenthal J, Moffit D. Direct Access Dental Hygienists' Perceptions Concerning Geriatric Curriculum in Entry-Level Dental Hygiene Programs. $J$ Dent Hyg. 2020;94(5):22-29.

14. Szabo KB, Boyd LD, LaSpina LM. Educational Preparedness to Provide Care for Older Adults in Alternative Practice Settings: Perceptions of dental hygiene practitioners. J Dent Hyg. 2018;92(6):16-23.

15. Reuben DB, Lee M, Davis JW, Jr., et al. Development and validation of a geriatrics attitudes scale for primary care residents. J Am Geriatr Soc 1998;46:1425-30. doi:10.1111/j.1532-5415.1998.tb06012.x

16. Carellis C, Kalberer N, Abou-Ayash S, Schimmel M, Wittneben J, Zitzmann NU, Besimo CE, Bornstein M, Müller F, Srinivasan M. Attitudes of dental students towards treating elderly patients. Swiss Dent J. 2021 [Accepted - IN PRESS].

17. Wiener RC, Shockey AT, Long DL. Dental hygiene students' perceptions of older adults. J Dent Educ. 2014;78(12):1623-1628.

18. MacEntee MI, Pruksapong M, Wyatt CC. Insights from students following an educational rotation through dental geriatrics. J Dent Educ 2005;69:1368-76.

19. Nitschke I, Clarenbach-Tran TH, Schlegel D, Reiber T, Sobotta BA. Attitudes of German undergraduate dental students towards the aged. Gerodontology 2015;32:3-12. doi:10.1111/ger.12043 
20. Westmoreland GR, Counsell SR, Sennour Y, et al. Improving medical student attitudes toward older patients through a "council of elders" and reflective writing experience. J Am Geriatr Soc 2009;57:315-20. doi:10.1111/j.1532-5415.2008.02102.x

21. Medical outcomes trust: Trust introduces new translation criteria. Medical Outcomes. Medical Outcomes Trust Bulletin. 1997:Accessed January 19, 2019. (http://www.outcomes-trust.org/bulletin/0797blltn.htm)

22.Leon S, Correa-Beltran G, Giacaman RA. Negative ageing stereotypes in students and faculty members from three health science schools. Gerodontology 2015;32:141-8. doi:10.1111/ger.12065

23. UNDESA. United Nations, Department of Economic and Social Affairs, Population Division. World Population Prospects: The 2017 Revision, Key Findings and Advance Tables. Working Paper No. ESA/P/WP/248. 2017.

(https://www.un.org/development/desa/publications/world-population-prospects-the-2017revision.html)

24. UNDESA. United Nations, Department of Economic and Social Affairs. World Population Ageing 2017 Highlights. 2017.

(https://www.un.org/en/development/desa/population/publications/pdf/ageing/WPA2017_ Highlights.pdf)

25. Chua MP, Tan CH, Merchant R, Soiza RL. Attitudes of first-year medical students in Singapore towards older people and willingness to consider a career in geriatric medicine. Ann Acad Med Singapore 2008;37:947-51.

26. Nochajski TH, Davis EL, Waldrop DP, Fabiano JA, Goldberg LJ. Dental students' attitudes about older adults: do type and amount of contact make a difference? J Dent Educ 2011;75:1329-32. 
27. Wood GJ, Mulligan R. Cross-sectional comparison of dental students' knowledge and attitudes before geriatric training: 1984-1999. J Dent Educ 2000;64:763-71.

28. Nunnally JC. Psychometric theory. 2 ed. McGraw-Hill; 1978. 


\begin{tabular}{|c|c|c|c|c|c|}
\hline Year of study (n) & Switzerland & Belgium & Canada & Total & $p$-value \\
\hline 1st year & 55 & 41 & 60 & 156 & \multirow{4}{*}{0.010} \\
\hline 2nd year & 52 & 30 & 43 & 125 & \\
\hline 3 rd year & 50 & 11 & 43 & 104 & \\
\hline Total & 157 & 82 & 146 & 385 & \\
\hline Age (mean $\pm S D$ ) & $25.38 \pm 4.6$ & $27.58 \pm 12.8$ & $25.95 \pm 12.3$ & $26.06 \pm 10.0$ & 0.276 \\
\hline \multicolumn{6}{|l|}{$\operatorname{Sex}[n(\%)]$} \\
\hline Women & $154(98.1 \%)$ & $69(84.1 \%)$ & $135(92.5 \%)$ & $358(92.99 \%)$ & \multirow{3}{*}{0.219} \\
\hline Men & $3(1.9 \%)$ & $11(13.4 \%)$ & $5(3.4 \%)$ & $19(4.94 \%)$ & \\
\hline Did not respond & - & $2(2.4 \%)$ & $6(4.1 \%)$ & $8(2.08 \%)$ & \\
\hline \multicolumn{6}{|l|}{ Nationality [n (\%)] } \\
\hline Swiss & $144(91.7 \%)$ & - & $1(0.7 \%)$ & $145(37.66 \%)$ & \multirow{5}{*}{$<0.001$} \\
\hline EU \& UK & $11(7.0 \%)$ & $73(89.0 \%)$ & - & $84(21.82 \%)$ & \\
\hline USA \& Canada & $1(0.6 \%)$ & - & $87(59.6 \%)$ & $88(22.86 \%)$ & \\
\hline Others & $1(0.6$ & $7(8.5 \%)$ & $50(34.2 \%)$ & $58(15.06 \%)$ & \\
\hline Did not respond & - & $2(2.4 \%)$ & $8(5.5 \%)$ & $10(2.60 \%)$ & \\
\hline \multicolumn{6}{|l|}{ Religion [n (\%)] } \\
\hline Christianity & $92(58.6 \%)$ & $24(29.3 \%)$ & $56(38.4 \%)$ & $172(44.68 \%)$ & \multirow{5}{*}{0.084} \\
\hline Islam & $19(12.1 \%)$ & $19(23.2 \%)$ & $17(11.6 \%)$ & $55(14.29 \%)$ & \\
\hline Hinduism/Buddhism & $1(0.6 \%)$ & $1(1.2 \%)$ & $7(4.8 \%)$ & $9(2.34 \%)$ & \\
\hline No religion/others & $19(12.1 \%)$ & $4(4.9 \%)$ & $16(11.0 \%)$ & $39(10.13 \%)$ & \\
\hline Did not respond & $26(16.6 \%)$ & $34(41.5 \%)$ & $50(34.2 \%)$ & $110(28.57 \%)$ & \\
\hline \multicolumn{6}{|l|}{ Marital Status [n (\%)] } \\
\hline Single & $127(80.9 \%)$ & $46(56.1 \%)$ & $89(61.0 \%)$ & $262(68.05 \%)$ & \multirow{5}{*}{$<0.001$} \\
\hline Married & $10(6.4 \%)$ & $14(17.1 \%)$ & $28(19.2 \%)$ & $52(13.51 \%)$ & \\
\hline Divorced & $2(1.3 \%)$ & $1(1.2 \%)$ & $5(3.4 \%)$ & $8(2.08 \%)$ & \\
\hline Common law partner & $6(3.8 \%)$ & $17(20.7 \%)$ & $13(8.9 \%)$ & $36(9.35 \%)$ & \\
\hline Did not respond & $12(7.6 \%)$ & $4(4.9 \%)$ & $11(7.5 \%)$ & $27(7.01 \%)$ & \\
\hline \multicolumn{6}{|c|}{ Living Situation [n (\%)] } \\
\hline Alone & $14(8.9 \%)$ & $13(15.9 \%)$ & $10(6.8 \%)$ & $37(9.61 \%)$ & 0.690 \\
\hline
\end{tabular}

This article is protected by copyright. All rights reserved 


\begin{tabular}{|l|r|r|r|r|}
\hline With partner/family & $38(24.2 \%)$ & $20(24.4 \%)$ & $29(19.9 \%)$ & $87(22.60 \%)$ \\
\hline Sharing & $10(6.4 \%)$ & $5(6.1 \%)$ & $12(8.2 \%)$ & $27(7.01 \%)$ \\
\hline With parents & $84(53.5)$ & $38(46.3 \%)$ & $76(52.1 \%)$ & $198(51.43 \%)$ \\
\hline With grandparents & - & - & $2(1.4 \%)$ & $2(0.52 \%)$ \\
\hline With parents and grand parents & $1(0.6 \%)$ & - & $2(1.4 \%)$ & $3(0.78 \%)$ \\
\hline Did not respond & $10(6.4 \%)$ & $6(7.3 \%)$ & $15(10.3 \%)$ & $31(8.05 \%)$ \\
\hline
\end{tabular}

This article is protected by copyright. All rights reserved 


\begin{tabular}{|c|c|c|c|c|}
\hline Year of study & Switzerland & Belgium & Canada & All centers \\
\hline \multirow[t]{2}{*}{$1^{\text {st }}$ year } & $3.75 \pm 0.39$ & $3.11 \pm 0.32$ & $3.28 \pm 0.37$ & $3.40 \pm 0.45$ \\
\hline & {$[3.6413,3.8544]$} & {$[3.0100,3.2145]$} & {$[3.1866,3.3781]$} & [3.3321, 3.4751] \\
\hline \multirow[t]{2}{*}{$2^{\text {nd }}$ year } & $3.44 \pm 0.36$ & $3.32 \pm 0.38$ & $3.27 \pm 0.37$ & $3.35 \pm 0.37$ \\
\hline & {$[3.3431,3.5427]$} & {$[3.1773,3.4668]$} & {$[3.1515,3.3802]$} & {$[3.2868,3.4197]$} \\
\hline \multirow[t]{2}{*}{$3^{\text {rd }}$ year } & $3.62 \pm 0.45$ & $3.50 \pm 0.33$ & $3.41 \pm 0.32$ & $3.52 \pm 0.40$ \\
\hline & {$[3.4880,3.7456]$} & {$[3.2725,3.7185]$} & {$[3.3129,3.5080]$} & {$[3.4411,3.5962]$} \\
\hline \multirow[t]{2}{*}{ Total } & $3.61 \pm 0.42$ & $3.24 \pm 0.37$ & $3.32 \pm 0.36$ & $3.42 \pm 0.42$ \\
\hline & {$[3.5389,3.6713]$} & [3.1591, 3.3229] & {$[3.2565,3.3739]$} & {$[3.3766,3.4604]$} \\
\hline $\mathrm{p}$-value & 0.001 & 0.002 & 0.114 & 0.010 \\
\hline \multicolumn{5}{|c|}{$\begin{array}{l}\text { Comparison of the GAS scores between the years of study for the various centers ( } p \text {-value: post-hoc Bonferroni test; } \\
\text { significance: } p<0.05 \text { ) }\end{array}$} \\
\hline Comparison & Switzerland & Belgium & Canada & All centers \\
\hline $1^{\text {st }}$ vs. $2^{\text {nd }}$ (p-value) & 0.0004 & 0.044 & 1.000 & 0.936 \\
\hline $1^{\text {st }}$ vs. $3^{\text {rd }}(p-v a l u e)$ & 0.294 & 0.005 & 0.221 & 0.086 \\
\hline $2^{\text {nd }}$ vs. $3^{\text {rd }}(p-v a l u e)$ & 0.093 & 0.478 & 0.185 & 0.008 \\
\hline \multicolumn{5}{|c|}{ Comparison of the GAS scores between the countries ( $p$-value: post-hoc Bonferroni test) } \\
\hline $\begin{array}{l}\text { Switzerland vs. } \\
\text { Belgium ( } p \text {-value) }\end{array}$ & \multicolumn{4}{|c|}{$<0.001$} \\
\hline $\begin{array}{l}\text { Switzerland vs. } \\
\text { Canada (p-value) }\end{array}$ & \multicolumn{4}{|c|}{$<0.001$} \\
\hline $\begin{array}{l}\text { Belgium vs. Canada } \\
\text { ( } p \text {-value) }\end{array}$ & \multicolumn{4}{|c|}{0.506} \\
\hline Overall ( $p$-value) & \multicolumn{4}{|c|}{$<0.001$} \\
\hline
\end{tabular}

This article is protected by copyright. All rights reserved 


\begin{tabular}{|l|c|}
\hline $\begin{array}{l}\text { Table 3. Influence of demographic parameters on the overall Geriatric Attitudes Scale (GAS) scores of the participating } \\
\text { centers }\end{array}$ \\
\hline Demographic parameters & p-value \\
\hline Age ${ }^{*}$ GAS & 0.118 \\
\hline Sex ${ }^{*}$ GAS & 0.314 \\
\hline Nationality ${ }^{*}$ GAS & $<0.001$ \\
\hline Religion ${ }^{*}$ GAS & 0.290 \\
\hline Marital status ${ }^{*}$ GAS & 0.05 \\
\hline Accommodation status ${ }^{*}$ GAS & 0.170 \\
\hline p-value: ANOVA; significance: $p<0.05$ & \\
\hline
\end{tabular}

This article is protected by copyright. All rights reserved 


\begin{tabular}{|c|c|c|c|c|c|}
\hline \multirow[t]{2}{*}{ Specific Questions } & \multicolumn{5}{|c|}{ Responses expressed in numbers (percentages) } \\
\hline & $\begin{array}{l}\text { Strongly } \\
\text { disagree }\end{array}$ & $\begin{array}{c}\text { Somewhat } \\
\text { disagree }\end{array}$ & Neutral & $\begin{array}{c}\text { Somewhat } \\
\text { agree }\end{array}$ & Strongly agree \\
\hline $\begin{array}{l}\text { SQ\#1: Geriatric dentistry is an important aspect of } \\
\text { the dental curriculum }\end{array}$ & $4(1.2 \%)$ & $14(4.3 \%)$ & $60(18.6 \%)$ & $134(41.6 \%)$ & $110(34.2 \%)$ \\
\hline $\begin{array}{l}\mathrm{SQ \# 2:} \text { The geriatric program in the teaching } \\
\text { curriculum is adequate }\end{array}$ & $6(1.9 \%)$ & $14(4.5 \%)$ & $170(54.7 \%)$ & $86(27.7 \%)$ & $35(11.3 \%)$ \\
\hline $\begin{array}{l}\text { SQ\#3: I am confident in treating the elderly on my } \\
\text { own independently }\end{array}$ & $4(1.3 \%)$ & $29(9.1 \%)$ & $58(18.1 \%)$ & $167(52.2 \%)$ & $62(19.4 \%)$ \\
\hline $\begin{array}{l}\text { SQ\#4: I am not confident in treating the elderly } \\
\text { patient unsupervised }\end{array}$ & $47(14.7 \%)$ & $68(21.3 \%)$ & $58(18.2 \%)$ & $91(28.5 \%)$ & $55(17.2 \%)$ \\
\hline $\begin{array}{l}\text { SQ\#5: I would like to have hands on experience in } \\
\text { treating the elderly patient during my undergraduate } \\
\text { curriculum }\end{array}$ & $6(1.9 \%)$ & $16(5.0 \%)$ & $51(15.8 \%)$ & $133(41.2 \%)$ & $117(36.2 \%)$ \\
\hline $\begin{array}{l}\text { SQ\#6: I would prefer to treat the elderly patients in a } \\
\text { clinic setting }\end{array}$ & $14(4.3 \%)$ & $44(13.6 \%)$ & $152(46.9 \%)$ & $82(25.3 \%)$ & $32(9.9 \%)$ \\
\hline $\begin{array}{l}\text { SQ\#7: I would prefer to treat the elderly patients in a } \\
\text { hospital setting }\end{array}$ & $28(8.6 \%)$ & $67(20.7 \%)$ & $143(44.1 \%)$ & $67(20.7 \%)$ & $19(5.9 \%)$ \\
\hline $\begin{array}{l}\text { SQ\#8: I would prefer to treat the elderly patients in } \\
\text { nursing home setting }\end{array}$ & $40(12.3 \%)$ & $65(20.1 \%)$ & $130(40.1 \%)$ & $76(23.5 \%)$ & $13(4.0 \%)$ \\
\hline $\begin{array}{l}\text { SQ\#9: Mobile dental clinics are a good solution for } \\
\text { elders without access to care }\end{array}$ & $8(2.5 \%)$ & $8(2.5 \%)$ & $32(9.9 \%)$ & $105(32.6 \%)$ & $169(52.5 \%)$ \\
\hline
\end{tabular}

This article is protected by copyright. All rights reserved 


\section{Figure Legends}

Figure 1.
Participant responses to the supplementary questions related to their geriatric curricula, confidence in treating elders, and preferred treatment setting for managing elderly patients. 


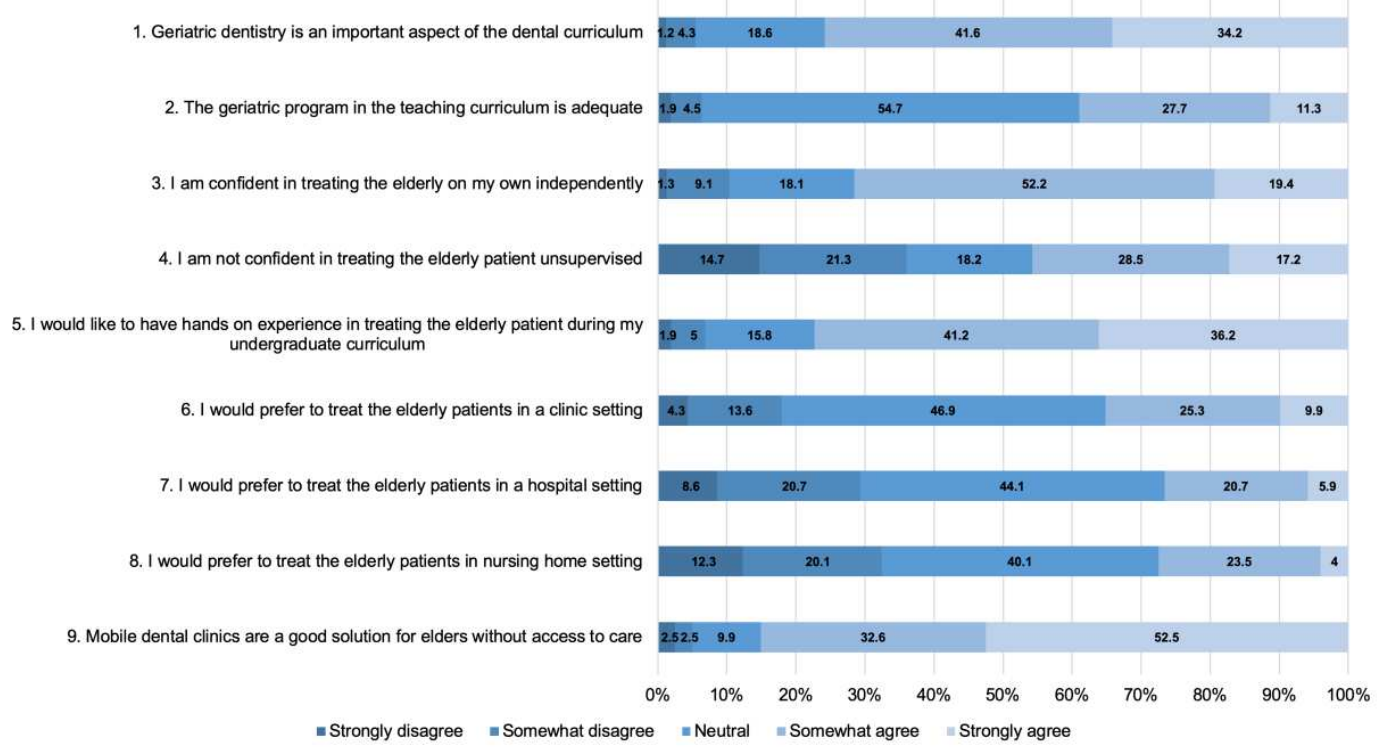

idh_12486_f1.jpg

This article is protected by copyright. All rights reserved 